\title{
Debates sobre gênero na docência: o professor do sexo masculino nas séries iniciais do Rio de Janeiro-Brasil e Aveiro-Portugal
}

\section{Discussions about gender in teaching: male teachers in primary education in Rio de Janeiro-Brazil and Aveiro-Portugal}

\author{
Amanda Rabelo ${ }^{1}$
}

\begin{abstract}
RESUMO
Este artigo centra-se em uma investigação sobre a figura do professor do sexo masculino que trabalha no ensino público do ensino primário, onde averiguamos os motivos e as consequências da escolha profissional destes docentes que se enveredam por uma área tipicamente associada com o feminino. Analisando questionários e entrevistas com estes professores são identificadas nas suas narrativas as questões que marcaram a opção pela docência fazendo um estudo comparativo entre duas regiões: Rio de Janeiro/ Brasil e Aveiro/Portugal. A presença de professores do sexo masculino na docência do ensino primário é uma forma de inserir as questões de gênero na educação e demonstrar que o homem também pode escolher essa atividade. Promove-se, então, discussões centradas nas representações de gênero que rondam o campo profissional da docência, neste artigo focadas mais nos resultados dos questionários.
\end{abstract}

Palavras-chave: professor do sexo masculino; gênero; escolha profissional.

${ }^{1}$ Doutora em Ciências da Educação pela Universidade de Aveiro, Portugal. Professora Adjunta do Instituto Noroeste Fluminense de Educação Superior (INFES) da Universidade Federal Fluminense (UFF), Rio de Janeiro, Brasil. Pós-Doutora em Ciências da Educação na Faculdade de Psicologia e Ciências da Educação na Universidade de Coimbra, projeto financiado pela FCT Fundação para a Ciência e a Tecnologia), Portugal.E-mail: amandaorabelo@hotmail.com 


\begin{abstract}
This article centered in the investigation about the figure of the male professor that works in the public education of the elementary school. We intend to inquire the reasons and the consequences of the professional choice of those professors that walk for an area typically associated with the feminine sex. Analyzing questionnaires and interviews with those teachers, the questions which had marked their option for teaching are identified in their narratives by means of making a comparative study between two regions: Rio de Janeiro (Brazil) and Aveiro (Portugal). The presence of male teachers teaching in the elementary school is a way to insert the issues of gender in education and show that man can choose this activity. It promotes, then, discussions centered on representations of gender that surround the professional field of teaching which, in this article, are more focused on the results of the questionnaires.
\end{abstract}

Keywords: male professor; gender; professional choice.

\title{
Introdução
}

Todo texto reflete e tece a subjetividade e a trajetória do autor, isso não difere dos provenientes de investigações acadêmicas: estes formam e deformam o seu próprio compositor, lapidam os ânimos que instigam a escrever e que permitem abrigar nos próprios pensamentos e ampliá-los.

Por isso, apesar de objetivarmos neste texto descrever algumas considerações sobre os poucos professores ${ }^{2}$ do sexo masculino que trabalham no ensino primário do ensino público do Estado do Rio de Janeiro no Brasil (RJ-BR) e do Distrito de Aveiro em Portugal (AV-PT) ${ }^{3}$, rever, ainda que de modo breve, o percurso realizado para desenvolver o tema pode trazer um pouco mais de clareza sobre as concepções subjacentes a este trabalho.

${ }^{2}$ Neste artigo, quando a palavra professor (ou professores) for mencionada ela refere-se ao sexo masculino. Quando esta palavra designar o conjunto do gênero masculino e do gênero feminino, utilizaremos uma linguagem não sexista, por exemplo, professor/a, professores/as, entre outras. Esta atitude baseia-se nas orientações para a eliminação do sexismo na linguagem. Ver, por exemplo: Recomendação n. ${ }^{\circ} 5$ (90) 4 do Comitê de Ministros aos Estados membros sobre a Eliminação do Sexismo na Linguagem (Conselho da Europa (1990), Rêgo (2004), Abranches \& Carvalho (2000)).

${ }^{3}$ Com base no trabalho de Rabelo (2008). 
O trabalho de mestrado que desenvolvemos ${ }^{4}$ envolveu discussões sobre a feminização do magistério e a escolha profissional das "normalistas" destes debates e das considerações finais esboçadas, novas questões que não eram alvo de tal estudo surgiram e tomaram forma de inquietações que precisavam ser resolvidas. Contudo, não podemos resolver todas as questões, pois muitos enigmas não serão resolvidos e outros terão que ser resolvidos a posteriori. Sábia descoberta que leva a outras buscas, que leva a outros descontentamentos, num ótimo ciclo vicioso...

Um deles foi a pequena quantidade de homens presentes nos cursos de formação de docentes para o ensino primário ${ }^{6}$ e o preconceito/discriminação de muitas pessoas com relação a eles, inclusive, algumas normalistas (colaboradoras da pesquisa anteriormente citada).

Nas observações efetuadas em universidades, cursos de formação docente e escolas públicas do Brasil, verifiquemos que muitos dos professores homens ingressam no magistério apresentando semelhantes motivos apontados pelas mulheres. Por exemplo: facilidade de estudo no curso de formação, entrada rápida no mercado de trabalho, alto índice de empregabilidade, entre outros. Contudo, uma afirmação de um diretor de um curso de formação de docentes do ensino primário lançou uma desconfiança sobre as justificativas de escolha pela carreira do magistério: os homens privilegiariam na escolha profissional o emprego e a possibilidade de transformação da sociedade e menor valor ao gosto por crianças (exaltado como uma das principais motivações feminina).

Este episódio gerou uma das dúvidas que persistiram ao fim do trabalho: será que é necessário "gostar" de criança para ser professor/a? Ou melhor, é suficiente gostar de criança para lecionar?

Queríamos constatar quais realmente eram os maiores impulsionadores da escolha dos poucos homens que se enveredam pela profissão docente, e porque esta é tão indisponível e inacessível a eles, sendo uma carreira considerada feminina e que (possivelmente em um esforço para que ela continue sendo específica de mulheres) acaba por discriminar tais "intrusos" que precisam afirmar-se em tal posto de trabalho se não quiserem dele abdicar.

${ }^{4}$ RABELO, A. A Memória das Normalistas do IESK de Campo Grande/RJ. Dissertação (Mestrado em Memória Social e Documento) - UNIRIO, Rio de Janeiro, 2004.

${ }^{5}$ Normalista era o nome dado no Brasil à aluna do antigo curso denominado normal (curso de nível médio/secundário) de formação de docentes do ensino primário do ensino fundamental.

${ }^{6}$ Utilizamos este termo de acordo com a nomenclatura recomendada pela UNESCO - Organização das Nações Unidas para a Educação, a Ciência e a Cultura e que já foi utilizada tanto no Brasil como em Portugal, atualmente denomina-se anos iniciais do ensino fundamental no Brasil e $1 .^{\circ}$ ciclo do ensino básico em Portugal. 
Constatamos, ainda, em alguns cursos de formação de professores/as deste nível de ensino que, mais recentemente, timidamente tem aumentado a procura dos homens pela docência, não obstante permanecem (ou quiçá até aumentam) os preconceitos (o que é confirmado por Abreu, 2002). Desta forma, nosso grande desafio é desmistificar o preconceito divulgado no RJ-BR (além de outras localidades do Brasil) de que os homens que optam pelo magistério apresentam características efeminadas, e/ou a ideia ainda mais frequente (tanto no Brasil quanto em Portugal) de que faltam condições aos homens para ensinar nesta primeira fase do ensino.

Esses foram os precursores da ideia geral do tema da tese de doutorado desenvolvido, que provavelmente também proporcionará outras inquietações tanto a nós como aos leitores que sobre ela se debruçarem, até porque a leitura e o entendimento dela depende do contexto do leitor, pois como afirmara Frei Betto (2002), "a cabeça pensa onde os pés pisam", assim não só abrimos este texto às questões de cada um, mas também ao complemento que cada um possa fazer diante delas, pois consideramos que todo trabalho está em devir, que tem como perspectiva ser fortalecido ainda mais em pesquisas e produções vindouras.

\section{O objeto e as questões metodológicas}

Portanto, a escritura que se segue dá conta dos resultados provisórios de uma busca centrada na figura do professor do sexo masculino que trabalha no ensino público ${ }^{7}$ do "ensino primário". Com esta investigação pretendemos, fundamentalmente, averiguar os motivos e as consequências da escolha profissional destes docentes que se enveredam por uma área tipicamente associada com o feminino. Identificamos nas suas narrativas/discursos as questões que marcaram/marcam a opção pelo magistério fazendo um estudo comparativo entre duas regiões: Rio de Janeiro-Brasil (RJ-BR) e Aveiro-Portugal (AV-PT).

Aproveitamos para explicar que o recorte espacial foi tomado e escolhido como ponto central de discussões e comparações com o intuito de captar as diferenças e semelhanças entre os dois locais, nunca esquecendo da influência crucial da colonização portuguesa sobre a cultura e a escola brasileira, mas também destacando as características locais como forma de perceber quais caminhos

${ }^{7}$ Que é um espaço de vivência/convivência educacional onde se visa formar o pensamento da maioria da população. 
diferentes podem ser traçados e que estes dependem dos vários condicionantes a que se são submetidos ${ }^{8}$.

Realizamos entrevistas narrativas semiestruturadas em 2006 com seis professores escolhidos ao acaso dentre uma amostra de 209 professores do ensino público que responderam no ano de 2005 a um questionário ${ }^{9}$ objetivo e subjetivo ${ }^{10}$, 60 do Distrito de Aveiro (Portugal) e 149 do Estado do Rio de Janeiro (Brasil) ${ }^{11}$.

Tais dados permitiram a análise da informação obtida e forneceram dados mais amplos (pela categorização, apreciação e quantificação das estatísticas e dos discursos escritos provenientes dos questionários), assim como possibilitaram situar as informações em vivências (nas narrativas de entrevistados), analisando os significados presentes e a sua relação com a sociedade, as suas instituições e os seus enunciados. A combinação destes processos de recolha de dados/discursos possibilitou-nos fazer o confronto entre o geral e o local, embora aqui neste artigo apresentaremos os resultados mais com base nos dados obtidos nos questionários.

Enunciada nesses termos a questão de partida, impõe-se referir que não consideramos este professor nem como um sujeito totalmente assujeitado nem integralmente senhor de si. Portanto, as vicissitudes que a ele se apresentam, tanto como tropeços, percalços, quanto como motivações ou imperativos de pessoas e instituições do seu entorno, contribuem para as suas opções e formam a sua subjetividade ${ }^{12}$.

${ }^{8}$ A escolha das regiões foi motivada pelo fácil acesso a elas. Ambas as regiões atendem a classes sociais diferenciadas e têm trechos urbanos e rurais. Sabemos que não podemos generalizar, mas encontramos dados que são apontados pelos professores em outras pesquisas como sendo nacionais.

${ }^{9}$ Que foi distribuído a todos os professores do sexo masculino do ensino público sobre o qual obtivemos dados e autorização das prefeituras e agrupamentos do Distrito de Aveiro (Portugal) e do Estado do Rio de Janeiro (Brasil).

${ }^{10}$ Com questões fechadas (de vários tipos: questões dicotômicas de sim e não, de múltipla escolha, de escala de valores) e outras abertas. Tomamos também alguns cuidados ao fazer um estudo comparativo transnacional para garantir a equivalência de construtos, unidades de medida e escalas, como: tradução adequada (ambos os países utilizam o mesmo idioma, mas existem diferentes palavras e expressões que poderiam tornar o inquérito ininteligível), denominar corretamente os níveis de ensino com nomenclatura diferente, enfim, procedimentos para que o referido instrumento de medida fosse interpretado da mesma maneira nos dois países.

${ }^{11}$ Os questionários foram enviados a todos os professores do sexo masculino em exercício letivo nas escolas públicas diretamente pelo correio ou por intermédio dos referidos órgãos administrativos. Foram distribuídos 113 questionários em AV-PT e 328 no RJ-BR, o que equivale a uma taxa de retorno, respectivamente, de $53 \%$ e $45 \%$.

${ }^{12}$ Termo este entendido de acordo com a concepção foucaultiana onde toda subjetividade é, ao mesmo tempo, uma tentativa de captar e moldar o sujeito pelos saberes e poderes, e uma reserva de resistência ou de fuga à captação de sua forma. 
Destaca-se a importância de tal investigação ao promover discussões centradas nas representações de gênero que rondam o campo profissional da docência, cabendo, então, questionar a normalização do magistério enquanto profissão aliada à temática do cuidado de crianças e mostrar que existem outros temas e outras vozes que ecoam nas escolas.

Os objetos de estudo não estão parados esperando para serem analisados, eles são processos que tentaremos compreender não somente com o olhar, mas também com a audição (além de outros sentidos) que tentam entender a visão dos outros com quem dialogamos. Mesmo assim não podemos deixar de considerar que as formas com que os objetos são percebidos e analisados são criações que envolvem a subjetividade de cada um e que ela é profundamente interligada com o contexto e as experiências vividas.

Para tal análise, o conceito da representação, enquanto construção de significado gerada no meio de relações de poder ${ }^{13}$, é apoio para perceber as potencialidades dos discursos que emergem sobre os gêneros e a sua relação com a profissão docente. Vale a pena destacar que tais representações não são fixas e moldadoras do pensamento dos indivíduos, mas modelos discutidos e divulgados diante das relações de poder mantidas com a nossa cultura e história.

Os textos de Mónica (1978) e Louro (2000) permitem-nos compreender que, apesar das representações terem utilidade social, isto não significa afirmar que a feminização do magistério foi um plano das classes dominantes ${ }^{14}$. Não houve uma decisão taxativa de que as mulheres entrariam na docência, houve uma associação de representações de aptidões necessárias para exercer o trabalho, políticas, cobrança das mulheres, necessidade de mais docentes, baixos salários, surgimento de outros trabalhos aos homens, entre outros, que fez com que os discursos começassem a circular com maior frequência.

Nessa linha, toda uma gama de enunciados se afirmou tentando marcar as competências morais do/a docente, vinculando-lhes inclusive o próprio gênero. Como as representações estão sempre em devir, ou seja, não são fixas e são continuamente e imperceptivelmente modificadas (pois funcionam como convenções sociais e não como regras inquebráveis), ressaltamos que estes discursos são apropriados pelos professores de diferentes formas: aceitando-os, alterando-os ou, mesmo, negando-os.

${ }^{13}$ Ver Hall (1997a, 1997b), Silva (2002), Louro (2000).

${ }^{14}$ Como explicam as autoras, de início, tanto as classes dirigentes quanto as próprias mulheres se encontravam divididas face à entrada delas nesta profissão, por isso, não foi nem uma benevolência diante da pressão, nem uma estratégia vitoriosa das classes dominantes. Contudo, vale lembrar que as pressões populares sempre ficaram subordinadas à estratégia das classes dominantes. 
Enfim, nos últimos tempos assiste-se a uma grande proliferação de estudos que interligam a profissão educacional às perspectivas de gênero, mas acabam por abordar a feminização do magistério de acordo com o ponto de vista das mulheres docentes. Mas e os homens? Não são ouvidos?

Ao destacar as vozes femininas nas atuais investigações educacionais, corre-se o risco de desconhecer o pensamento dos homens que se enveredam pelo magistério. O mundo da educação, no que concerne o magistério do ensino primário, gira atualmente em torno do feminino (inclusive certos estudos, projetos de governo, programas de reformas educacionais, entre outros). Quando se trata do olhar masculino do professor primário quase não são encontradas referências ao tema; e mais, reafirmam-se os preconceitos e discursos que frequentam a sociedade contemporânea. Assim, o professor homem se torna um "corpo estranho no cotidiano da escola primária".

Reconhecemos que a maioria dos homens desconhece a docência como possibilidade de trabalho, muitas vezes, ocasionada pela pouca divulgação do campo do magistério neste segmento como profissão acessível a ele ${ }^{15}$. Esse silenciamento é potencializado no senso comum e pelas diversas formas midiáticas, tais como: revistas, jornais, programas televisivos, filmes, entre outros meios de comunicação em massa.

Percebemos que quando há uma divulgação específica do magistério para o homem existe maior possibilidade de escolha. Por exemplo, nos apelos ao voluntariado os homens também se disponibilizam. Assim, dependendo da forma que a sociedade apresenta e representa as profissões no imaginário social, elas passam a se tornar possíveis.

A escolha profissional é historicamente indissociável do postulado geral segundo o qual há indivíduos para cada tipo de ofício. Além disso, este problema está intimamente relacionado com referenciais de classe, gênero, raça - entre outras formas de divisões sociais - pois admitimos que tais considerações funcionam pessoalmente como apropriações/aprendizagem dos jogos estratégicos e relacionais em que cada um constituiu-se a si mesmo e, ao mesmo tempo, contribui para a continuação e/ou modificação dos discursos.

Defendemos, então, a importância de captar a realidade concreta em que se constroem/construíram estes professores que em suas condições de gênero optaram pela profissão, olhando com particular interesse para os movimentos que partem de situações concretas e dos sujeitos que realizam a história de nosso cotidiano escolar.

${ }^{15}$ Inclusive em alguns testes "vocacionais" divulga-se a necessidade da presença de aspectos considerados femininos associados aos cuidados para lidar com pessoas, principalmente crianças. 
Neste sentido, de acordo com o pensamento de Reis (2002), tomam forma as correlações de força, as formas de relações de poder dominantes, as condições trabalhistas, as tradições docentes e culturais, que constituem as tramas que se amalgam no processo de educar. Assim, procuramos desvelar os "comos", os porquês e os lugares onde se assinalaram/assinalam as contínuas descontinuidades ${ }^{16}$ e rupturas nas práticas discursivas e não discursivas, capazes de desconstruírem uma história de formação linear e acrítica.

A partir de 209 inquéritos respondidos ${ }^{17}$ e 6 entrevistas efetuadas com professores do sexo masculino, que atuam no magistério público do ensino primário de RJ-BR e de AV-PT, investigamos os motivos que influenciaram sua opção profissional, sua relação com o magistério do ensino primário e a receptividade das pessoas em relação à sua escolha profissional e atividade docente: Sofrem preconceitos? Que desafios ele enfrenta em sua condição de gênero? Como é recebido pela criança nesta faixa etária? Que mecanismos instituintes têm levado alguns a sucumbir e outros a continuar no magistério? Como a demarcação de papéis profissionais lhe tem afetado?

Como alguns estudos apontam (BERTELLI, 2006; PINCINATO; BUENO, 2004; WILLIAMS, 1995), para entendermos as desvantagens (e se existem vantagens) da mulher no mercado de trabalho é essencial examinar as vantagens/ desvantagens do homem. Nosso estudo centrou-se nesse esforço de compreender as motivações dos homens que escolhem a profissão de professor primário, assim como as consequências de tal opção, como facilidades, dificuldades e preconceitos que estes encontram por serem a minoria neste segmento.

O tema e o objeto/sujeito do presente estudo nutrem-se das fagulhas vívidas em que se entrelaçam emoções e imagens presentes nas memórias, narrativas e discursos, colhidas de forma escrita e falada - que não se limitam à vida das pessoas pesquisadas, mas, também, das instituições sociais e formações mais amplas em que se inscrevem e que dependem da produção, veiculação e consumo de imagens, introduzidos pelos meios de comunicação, pelos discursos sobre técnicas, e demais procedimentos e práticas de si.

Consideramos, então, que entre o indivíduo e o seu entorno há uma relação dinâmica, existindo um vínculo indissociável entre o subjetivo e o objetivo que não pode ser traduzido somente por números, entretanto, não deixamos de nos reportar também a dados quantitativos, obtidos tanto em órgãos oficiais do Brasil e de Portugal, quanto nos questionários distribuídos.

${ }^{16}$ Não há aqui uma contradição, pois esta junção de opostos segue as indicações de Foucault acerca das rupturas históricas não acontecerem somente em um momento e de uma forma brusca, mas continuamente em um processo acumulativo e constante.

${ }^{17} 60$ do Distrito de Aveiro e 149 do Estado do Rio de Janeiro. 
A combinação dos discursos escritos presentes nos questionários distribuídos e das narrativas dos professores entrevistados se completam, pois entendemos que os inquéritos complementam e confirmam ainda mais a pesquisa com a narrativa dos entrevistados, e estas possibilitam situar as informações em vivências ${ }^{18}$. Além disso, esta relação permite confrontar o geral e o local, sendo necessário tecer o específico (das questões de gênero) com o conjunto de relações com a sociedade, as suas instituições e os seus enunciados.

Considerando as ponderações de vários autores (que tratam de narrativas, história oral ou de vida) entendemos que não há uma memória específica para homens ou mulheres, as memórias diferenciam-se de acordo com as experiências sociais e as trajetórias de cada indivíduo, assim as mulheres podem ter memórias diferentes das dos homens por causa das ocupações e posições sociais que geralmente têm.

De acordo com esta reflexão, analisamos as narrativas dos homens que optam por um ofício considerado feminino. Somente desta forma é possível perceber estes discursos que podem estar entrelaçados tanto às considerações sociais que tentam domar as formas de pensar dos indivíduos, quanto de novos olhares sobre elas. Entretanto, não dividimos o pensamento das mulheres e dos homens, optamos por este recorte como forma de entender a criação dos papéis sociais, considerados adequados aos homens e mulheres, e a formação das identidades de gênero.

Com base na citação de Fentress e Wickham (1992): A palavra escrita não é um espelho dos nossos pensamentos [...]. Nada do que escrevemos é tão disperso e desordenado como nosso processo de pensamento, percebemos que o recurso metodológico da narrativa não possibilitará atingir a contínua mobilidade e fluidez do nosso pensamento, mesmo assim ela é essencial para apreciar e criticar fatos que dizem respeito aos pensamentos ainda não estudados de um grupo e dos fatores que levam um indivíduo a agir de determinada maneira.

A narrativa permite compreender a complexidade das histórias contadas pelos indivíduos sobre os conflitos e dilemas de suas vidas, facilitam o contato com as experiências singulares e as "pequenas histórias" de indivíduos, grupos e comunidades. Botia (2002) entende-a como a qualidade estruturada da experiência percebida e vista como um relato, captando a riqueza e os detalhes dos significados nos assuntos humanos, tendo como base as evidências do mundo da vida. Reconstrói-se a experiência refletindo sobre o vivido, esclarecendo processos subjetivos do cotidiano humano e significando o sucedido.

${ }^{18}$ Assim como as informações também permitiriam que as vivências pudessem ser analisadas no que têm de singular ou comum. 
A partir desse aporte histórico será possível entrelaçar os dados e analisar os modos de transmissão dos valores e das descontinuidades e rupturas que são efetuadas nos discursos dos seis professores entrevistados. O trabalho limita-se a este número de entrevistas por causa da impossibilidade de se fazer e analisar, com qualidade, uma grande quantidade de entrevistas abertas.

Para efetuar essa delimitação tomamos por base o fato ressaltado por Blanchet e Gotman (2001) de que a quantidade necessária de entrevistas é, de modo geral, de tamanho mais reduzido que a de um inquérito por questionário, pois as informações provenientes das entrevistas são validadas pelo contexto e não têm necessidade de sê-lo pela sua probabilidade de ocorrência ${ }^{19}$.

Foram captadas nas narrativas e discursos, contidos tanto nos questionários quanto nas entrevistas, as representações que elas carregam, analisando as preeminências que tentam fixar significados à profissão e determinar escolhas aos indivíduos, assim como as suas fluências e as potencialidades de emancipação.

Michel Foucault (1990) contribui para esta análise, na sua definição das práticas de si como um conjunto de técnicas de poder que incitam o sujeito a agir e pensar adequando-se aos princípios morais da sua época, mas, ao mesmo tempo, o ser humano é formado através de mecanismos para relacionar-se consigo mesmo e a reconhecer-se como certo tipo de sujeito. Estas práticas são as bases sobre as quais as estratégias de subjetivação têm operado como formas de classificação, representação, quantificação, sistematização, transmissão de informação, com o propósito de reinventar maneiras de divisão espaço-tempo que tentam configurar os indivíduos, contudo, ao mesmo tempo, os sujeitos apropriam-se destas operações de saber-poder de diferentes formas.

Verificamos, para além do já anunciado, como estas práticas são percebidas pelos professores e como eles agem para demarcar seus lugares profissionais e, até mesmo, identificar os motivos de continuarem e desejarem se aposentar na profissão (ou não), ou, ainda, se ela serve somente como um trampolim para outros ofícios.

\section{Alguns dados contextualizadores}

Ao mesmo tempo em que os homens se distanciam do magistério, as prescrições sobre a maneira de educar são baseadas em um modelo masculino de determinações, porque o controle em geral sempre esteve nas mãos dos homens,

\footnotetext{
${ }^{19}$ Não precisam ser validadas por uma amostra matematicamente delimitada.
} 
ou seja, eles sempre estiveram mais nos órgãos de administração e gestão de todas as áreas, inclusive na educacional (muitos autores destacaram/destacam esta preponderância). Não podemos deixar de ressaltar aqui que mesmo quando as mulheres são detentoras do poder, isto não impede que estas possam exercê-lo de uma forma usual, isto é, masculina.

Como existem formas diferentes de enxergar o mundo, a diferenciação de gêneros acaba trazendo implicações para o magistério, principalmente nos discursos das competências necessárias para ensinar crianças mostrando-os como atributo feminino, desta forma, o sexo masculino historicamente diminuiu drasticamente a sua participação nos setores educativos, tanto na área administrativa quanto na atuação pedagógica junto às crianças. Alguns dados colocados a seguir nos ajudam a comprovar essa situação.

Mónica (1978) destaca que o Estado Novo em Portugal ${ }^{20}$ diferenciou-se pelo crescente recrutamento de professoras e regentes escolares ${ }^{21}$, o que efetivou a feminização do magistério: em 1911 as mulheres eram 54\%, em 1916 eram 61\%, em 1926 eram 67\% e em 1949 já eram 73\%. No entanto, o número de regentes do sexo feminino era ainda maior, em 1940 eram 86\% e em 1942 eram 87\%.

Em outro estudo, organizado por Carneiro (2000), que analisa dados posteriores ao 25 de Abril de $1974^{22}$, o ensino primário (oficial e particular) é demarcado como sendo quase totalmente exercido por professoras, pois em 1995/1996 o sexo masculino era cerca de 7\% na docência, valor sensivelmente idêntico desde o ano letivo 1974/1975. Atualmente a taxa de feminização, medida de 1994/1995 a 2003/2004, continua indicando alto índice de mulheres no segmento que vai de 92,6\%, em 1994/1995, a 91\% em 2003/2004³ (GIASE, 2006).

${ }^{20}$ Estado Novo (ou II República) é o nome do regime político autoritário e corporativista (considerado ditatorial) que vigorou em Portugal, sem interrupção, de 1933 a 1974, embora com alterações. É conhecido também como Salazarismo, contudo é mais correto aplicar este nome ao período em que António de Oliveira Salazar governou, de 1932 até ao seu afastamento por doença em 1968. Ao período seguinte, conduzido por Marcelo Caetano e que se estendeu até a Revolução do 25 de Abril de 1974, deu-se o nome de Marcelismo.

${ }^{21}$ Os regentes escolares atuavam como docentes, mas sem preparação/formação profissional.

${ }^{22} \mathrm{O} 25$ de Abril, ou a Revolução dos Cravos, são as designações dadas ao levantamento militar que derrubou, num só dia, o regime político do Estado Novo, sem grande resistência do governo, que cedeu perante o movimento militar, apoiado pela larga maioria da população. O levantamento foi conduzido pelos oficiais intermédios da hierarquia militar. Considera-se, em termos gerais, que esta revolução devolveu a liberdade ao povo português (denominando-se "Dia da Liberdade" o feriado instituído em Portugal para comemorar a revolução no dia 25 do mês de Abril).

${ }^{23}$ Separando o ensino público do privado, a taxa de feminização fica, no ensino público, praticamente igual à destacada acima, mas no ensino privado há alteração, sendo de $95,7 \%$ em 1994/1995, reduzindo a $87,2 \%$ em 1999/2000. 
Nos dados que recolhemos junto aos agrupamentos ${ }^{24}$ de AV-PT, referentes ao ano letivo 2004/2005, os professores do sexo masculino eram $10,75 \%$ dos/ as docentes em exercício no ensino público, já nas áreas administrativas da escola havia $17,86 \%$ do sexo masculino. Fazendo uma proporção do número de mulheres em exercício docente primário em comparação às professoras provenientes do mesmo segmento que exercem atividades administrativas na escola, estas seriam $9,7 \%$, já os homens seriam $15 \%{ }^{25}$.

No Brasil, na estatística apresentada pelo INEP - Instituto Nacional de Estudos e Pesquisas Educacionais Anísio Teixeira (2003), referente ao ano de 2001, as mulheres na 4. ${ }^{a}$ série do ensino fundamental (oficial e público) seriam $92,1 \%$ dos/ as docentes de português e $91,1 \%$ de matemática ${ }^{26}$. Já na região Sudeste (região em que se situa o RJ-BR) seriam 97,4\% dos/as docentes de português e 96,4\% dos professores de matemática ${ }^{27}$. Assim, nesta região alguns fatores reduzem mais ainda a quantidade de homens (talvez a facilidade de conseguir outros empregos ou, mesmo, o preconceito existente em relação ao homem nesta profissão).

Nos dados recolhidos com as secretarias de educação e municípios ${ }^{28}$ do RJ-BR, referentes ao ano letivo de 2004, os professores do sexo masculino eram

${ }^{24} \mathrm{O}$ agrupamento de escolas é uma unidade organizacional, com órgãos de administração e gestão, constituída por estabelecimentos de educação pré-escolar e de um ou mais níveis e ciclos de ensino, a partir de um projecto pedagógico comum (Ver Decreto-Lei n. ${ }^{\circ} 115-\mathrm{A} / 98$, art. 5. ${ }^{\circ}$, Portugal). Contribuíram com esta investigação os seguintes agrupamentos: Águeda, Aguada de Cima, Fermentelos, Valongo do Vouga, Branca, S. João de Loure, Albergaria-a-Velha, Anadia, Vilarinho do Bairro, S. Bernardo, Cacia, Esgueira, Oliveirinha, Eixo, Aradas, Aveiro, Estarreja, Avança, Pardilhó, Ílhavo, Gafanha da Encarnação, Gafanha da Nazaré, Murtosa, Torreira, Oliveira do Bairro, Oiã, Válega, Esmoriz, Ovar, Maceda, Sever do Vouga, Vagos.

${ }^{25}$ As atividades de administração escolar em Portugal não afastam necessariamente o/a professor/a da atividade docente, ele muitas vezes acumula as duas atividades.

${ }^{26}$ Em geral, neste segmento, tanto no Brasil quanto em Portugal, impera a monodocência (docentes únicos), no entanto, no Brasil, algumas escolas (mormente as particulares) optam pela divisão de professores/as por disciplina, principalmente em séries mais adiantadas desta fase de ensino, como a $3 .^{\mathrm{a}} \mathrm{e} 4 .^{\mathrm{a}}$ séries.

${ }^{27}$ Aproveitamos para fazer uma crítica sobre esta forma de disposição dos dados, pois ao invés de fazer uma média geral dos/as docentes por gênero no ensino primário (de 1. ${ }^{a}$ a $4 .{ }^{a}$ ) do ensino fundamental, apresenta somente as percentagens da $4 .^{a}$ série (a última série do segmento). Até porque esta é apontada por autores e pelos próprios professores como uma das séries preferidas pelos docentes do sexo masculino.

${ }^{28}$ Contribuíram com esta investigação os seguintes: Angra dos Reis; Aperibé; Araruama; Areal; Arm. Búzios; Arraial do Cabo; Belford Roxo; Carapebus; Carmo; Casemiro de Abreu; Com. Levy Gasparian; Itaperuna; Itatiaia; Japeri; Miguel Pereira; Miracema; Nilópolis; Nova Friburgo; Paty do Alferes; Paracambi; Paraíba do Sul; Piraí; Porciúncula; Queimados; Quissamã; Rio Bonito; Rio de Janeiro; Sto. Antônio de Pádua; S. Fidélis; S. Franc. ${ }^{\circ}$ de Itabapoana; S. João de Meriti; S. José de Ubá; S. José do Vale do Rio Preto; S. Pedro da Aldeia; S. Sebastião do Alto; Sapucaia; Saquarema; Silva Jardim; Valença; Varre-Sai; Vassouras. 
1,98\% dos docentes em exercício no ensino público, já nas áreas administrativas da escola havia $2,60 \%$ do sexo masculino. Proporcionalmente ao número de mulheres em exercício docente no ensino primário, as professoras provenientes das mesmas séries que exercem atividades de gestão na escola seriam $28,55 \%$, já os homens seriam 33,08\%.

Comparando as informações percebemos que nos dois países a feminização do magistério no ensino primário aconteceu. Porém no Brasil (e mais especificamente na região Sudeste e no RJ-BR) a percentagem de homens nesta fase de ensino é ainda menor, qual será o motivo desta diferença? Uma das nossas hipóteses é de que o preconceito existente contra o homem que escolhe ser professor deste segmento o afasta desta área, além do salário desta profissão no Brasil ser pouco atrativo ${ }^{29}$.

O contexto histórico e político sobre o qual aconteceu a feminização do magistério no Brasil e em Portugal é de uma sociedade que demarca bem os papéis masculinos e femininos (transmitidos ao Brasil pela colonização portuguesa) comumente denominada patriarcal. Nesta perspectiva histórica ocorre a feminização do magistério (que começa a se demarcar a partir do fim do século XIX) e o êxodo dos homens da profissão no âmbito do magistério do ensino primário. Contudo, em vez de querer localizar uma essência deste acontecimento, prefirimos as perspectivas que diagnosticam os discursos que circulavam e a preponderância de alguns sobre outros, envolvendo uma discussão sobre o poder.

Muitos autores, como Bruschini e Amado (1988), Almeida (1996), entre outros, analisam essa feminização e o consequente abandono do magistério pelos homens tomando como eixo de discussão a desvalorização do magistério, posto que, no discurso do senso comum, historicamente, se fez presente a ideia amplamente divulgada (tanto no Brasil quanto Portugal) de que as mulheres, não provedoras das famílias, poderiam trabalhar por "sacerdócio", então poderiam ganhar menos que os homens. Este é um fato muito importante, tendo em vista que a escola estava estendendo suas funções para a educação do povo e precisava-se cada vez mais de profissionais. Contudo, com as estratégias de controle que se exercem sobre as mulheres, as funções docentes passam a ser alvo de prescrições e determinações cada vez maiores, tirando a autonomia do profissional.

${ }^{29}$ A média salarial de um/a docente de $1 .{ }^{\text {a a }} 4 .^{\text {a }}$ série no Brasil em 2001 era de $\mathrm{R} \$ 461,67$ e da região Sudeste R \$599,19. A título de comparação, o salário mínimo no mesmo ano era R \$180,00, a média salarial brasileira de um policial civil $\mathrm{R} \$ 1.510,64$, de um agente administrativo público $\mathrm{R} \$$ 911,82 , além disso, um/a docente de 5. a 8 . $^{\text {a }}$ série ganha em média quase $30 \%$ a mais do que o de 1. ${ }^{\mathrm{a}}$ a $4 .^{\mathrm{a}}$ série (BRASIL, 2003). Vale a pena destacar que o vencimento inicial de um/a professor/a é ainda menor do que esta média. Para mais informações sobre tal análise ver Rabelo (2010). 
Outros autores, como Apple (1988) e Demartini \& Antunes (1993), mostram como a situação apresentada serviu aos interesses patriarcais e econômicos, na medida em que a mulher continuaria voltando suas atenções para atividades associadas ao âmbito considerado privado (doméstico, ligado ao cuidado de crianças) e, ao mesmo tempo, seria um profissional na esfera pública, atendendo a uma duplicidade de papéis ligados ao capital e à sua reprodução, na realização do trabalho doméstico.

No entanto, Louro (2000) lembra que foram (e são) muitas as práticas docentes, e que não se pode simplificar e dizer que há uma única concepção de magistério nem que a sua feminização foi bem aceita por toda a sociedade. Mas a multiplicidade não significa que todas foram consideradas socialmente do mesmo modo. Algumas dessas práticas tiveram mais força para se impor, seja por terem sido desenvolvidas por grupos dominantes, seja por serem as que interessava fixar como "verdadeiras" práticas docentes, algumas dessas representações ganham autoridade do óbvio, do senso comum, a tal ponto que se suprime que é uma representação. Talvez por isso acaba-se por apagar as diferenças e falar no singular, como se as identidades pudessem ser unificadas. Professores e professoras foram, e são, objetos de representação (sempre estreitamente ligada ao poder).

Os homens distanciaram-se progressivamente do magistério do ensino primário por vários motivos, possivelmente por causa do surgimento de outras oportunidades de emprego, dos baixos salários e do controle que aumentava, ficando mais atrativas outras áreas de trabalho. Todavia, outras influências vieram associar-se - a exemplo dos discursos que conferiam ao magistério uma imagem articulada à maternidade - e estas possibilitaram o seu afastamento da docência deste segmento passando, na maioria das vezes, à esfera da gestão da educação. Como descreve Carvalho (1998, p. 14-15), quase todos os seus entrevistados narraram pressão para que ascendessem na carreira, seja lecionando para séries mais avançadas, seja assumindo cargos administrativos. Quase todos incorporavam em seus planos futuros deixar o ensino primário, mesmo aqueles que apresentavam compromissos com as crianças.

No entanto, mesmo que, nos dados recolhidos, os professores do sexo masculino do ensino primário que exercem atividades administrativas estejam em uma proporção um pouco maior (o que mostra que tem aumentado a quantidade de mulheres nestes setores também), estes quantitativamente não são mais a maioria nos cargos de gerência educacional referente a estes segmentos ${ }^{30}$.

${ }^{30} \mathrm{O}$ que não significa que estes não sejam maioria em cargos de direção de escolas em outros níveis educacionais, nem em ocupações de chefia nos gabinetes de chefia da educação. 
Como foi apreciado, as mulheres têm se apresentado como paradigma de trabalhador na educação, pretende-se, então, deixar falar as poucas vozes que representam o olhar do homem sobre a prática pedagógica no ensino primário, e mostrar que a docência infantil não é um atributo apenas feminino.

Enfim, buscamos problematizar a forma como os professores foram constituídos historicamente de forma híbrida, heterogênea, na relação complexa entre pessoas, coisas e forças. Situar este estudo nos estudos representacionais e narrativos conduz à explicitação principal de rejeição das antinomias porque estas engessam a compreensão dos sujeitos e suas ações, ao contrário, procuramos apreender as realidades sociais como construções históricas e cotidianas englobantes.

\section{Achando o Brasil e descobrindo Portugal - os primeiros indícios da investigação}

Procurar-se-á problematizar aqui os principais pontos destacados pelos professores. A priori, deixamos aqui o nosso pesar por não podermos apresentar os entrevistados da forma como gostaríamos. A necessidade de sermos sucintos não permite neste texto a utilização deste aparato, que possibilitaria mostrar que não discorremos sobre qualquer professor (nem da coletividade deles), escrevemos sobre uma rede composta de pessoas que têm sentimentos, histórias, anseios, percepções. Por isso, pontuar uma maioria ${ }^{31}$ das respostas sobre determinado assunto não é só o que importa, mas o conteúdo e a relação que elas têm com o contexto de cada indivíduo.

Apesar destas considerações, apresentaremos neste texto alguns dados provenientes dos questionários, com algumas análises, relacionando-as com as entrevistas efetuadas, destacamos, no entanto, que estas apreciações serão aprofundadas em um trabalho posterior.

\section{A escolha da profissão e níveis de apoio}

Uma das questões mais relevantes deste estudo é apreender a motivação da escolha profissional dos professores. Importa, inicialmente, destacar que

${ }^{31}$ Aspecto quantitativo. 
poucos professores marcaram apenas uma razão para a escolha, só $17 \%$ dos portugueses e $12 \%$ dos brasileiros marcaram apenas uma razão, a maioria de AV-PT (50\%) marcou duas opções e a maioria do RJ-BR (34\%) marcou três opções, mas existiram alguns inquiridos que marcaram até oito opções. Estes dados indicam que dificilmente um só fator leva a uma escolha profissional, geralmente são vários aspectos que interferem nesta opção, como também conclui Fernandes (2004) na sua investigação.

Dos inquéritos distribuídos descrevemos na tabela a seguir as distribuições das respostas com relação à escolha profissional:

\begin{tabular}{|l|c|c|}
\hline Justificativas de escolha profissional (\%) & AV-PT & RJ-BR \\
\hline Por gostar de ser professor & 78,3 & 80,5 \\
\hline Por gostar de crianças & 58,3 & 57,0 \\
\hline Pela tentativa de fazer mudanças na sociedade & 20,0 & 51,7 \\
\hline Foi a melhor opção dentre as existentes & 21,7 & 23,5 \\
\hline Por ter tido um ótimo professor/a que lhe inspirou & 13,3 & 20,1 \\
\hline Pela facilidade de inserção profissional & 8,3 & 17,4 \\
\hline Existe um(ou mais)professor/a na família que lhe motivou & 11,7 & 13,4 \\
\hline Foi influenciado pela família a seguir esta carreira & 6,7 & 10,7 \\
\hline Por falta de opção & 1,7 & 5,4 \\
\hline Um/a amigo/a lhe sugeriu & 1,7 & 4,0 \\
\hline Foi o curso para o qual obteve média de entrada & 3,3 & 2,0 \\
\hline Pela facilidade de ascensão profissional & 0 & 2,7 \\
\hline Foi obrigado pela família a seguir esta carreira & 1,7 & 0,7 \\
\hline Por gostar de exercer autoridade & 0 & 1,3 \\
\hline Outro & 3,3 & 5,4
\end{tabular}

Dos dados apresentados, inferimos algumas observações importantes para a compreensão das motivações e as questões de gênero na escolha profissional. O gosto pela profissão aparece com maior frequência nas respostas (com destaque nas explicações para a transmissão/partilha de conhecimentos, o gostar de ensinar e formar, a aspiração profissional a partir de uma experiência docente e o encanto pela escola/estudos), ou seja, a maioria destes professores escolheu a profissão porque gosta.

Porém, o segundo valor mais elevado encaminha para uma "descoberta": homem também gosta de crianças (e por que não?). Isto significa que não só as mulheres são motivadas pelo "gostar de crianças" na sua escolha profissional, mas os homens também exaltam nas suas explicações a sua facilidade para lidar com os "pequenos": a paciência, o amor, a possibilidade de ajudá-los a crescer e, 
também, de aprender com eles. Esta grande quantidade de respostas possibilita analisar como as questões de gênero têm se modificado na nossa sociedade, pois os homens permitem demonstrar a sua sensibilidade, paciência sem medo de serem estigmatizados.

Ou seja, estes dados confirmam uma das observações de Carvalho (1998), sobre alguns professores que escolhiam a profissão por vocação e gosto por crianças, e contraria a explicação de Abreu (2002), de que a escolha dos homens está mais associada com a falta de emprego em outras áreas, e a consideração de Catani, Bueno e Sousa (2000, p. 54-55) de que os homens que se dirigem ao magistério passam por um processo distinto do das mulheres, que seriam mais orientadas por uma lógica de "destinação", ao contrário, os homens teriam sua escolha revelada mais tardiamente, mais associada com a relação com o conhecimento estabelecido no âmbito universitário “e não por referência às 'vocações' ou tendências a 'gostar de crianças' como razões que por vezes são invocadas pelas mulheres para justificar/explicar a opção pelo ensino".

Teresa Sarmento (2002, p. 11) em Portugal também assinala, com relação à educação de infância, que "as razões apontadas pelos educadores são do mesmo teor das razões apresentadas pelas educadoras, ou seja, o gosto em trabalhar com crianças", assim, podemos perceber que não existem grandes diferenças de gênero na escolha profissional dos homens e mulheres pelo magistério. Mas isso não impede que a escolha pela profissão docente muitas vezes seja "feita em detrimento de outras opções possíveis, com a plena consciência da baixa representação social da profissão e da associada baixa remuneração" (SARMENTO, 2002, p. 6).

$\mathrm{O}$ terceiro valor mais significativo na escolha pela docência enaltece a busca "quase" utópica ${ }^{32}$ da transformação da sociedade, justificada na possibilidade de mudar o mundo a partir "do seu futuro" (as crianças), na própria transformação da vida destas crianças e das desigualdades, motivando-as e oferecendo oportunidades de informação.

Entretanto, também aparecem a opção pelo magistério como melhor escolha possível, a facilidade de inserção profissional, a falta de opção, a obtenção de aprovação (média de entrada) para este curso e a facilidade de ascensão que são motivações associadas com questões de empregabilidade, rentabilidade, necessidade de emprego e falta de oportunidades ${ }^{33}$. Além disso, ainda que de forma minoritária

${ }^{32}$ Utilizamos este "quase" porque também partilhamos e acreditamos um pouco nesta utopia, contudo percebemos que uma verdadeira transformação passa por uma complexidade bem maior, mas é verdade que para muitas crianças um bom docente pode fazer a diferença.

${ }^{33}$ No estudo de Pincinato e Bueno (2008) praticamente todos os seus entrevistados, ao completarem os seus estudos ginasiais, tinham como única opção possível ser professor, pois precisavam ajudar nas despesas da casa ou assumir a partir daquele momento as próprias contas. 
(ou pouco assumida?), o desejo de autoridade também aparece como motivação, bem como a liberdade de gerir o seu trabalho e de conciliá-lo com outras atividades.

Por fim, a escolha inspirada por um exemplo de professor/a, pela família (ou o exemplo da família), ou por um amigo(a) invocam as pessoas que interferem e influenciam nas opções de cada um. Por isso, as considerações dos outros sobre a escolha profissional do homem pelo magistério também devem ser analisadas para perceber as interferências, lutas e dificuldades que os professores inquiridos passaram para optar pela sua profissão.

Ao contrapor a satisfação e a insatisfação dos familiares, vizinhos, parentes, com a opção de carreira efetuada, percebemos que a maioria dessas pessoas apoia esta escolha. O maior apoio vem em primeiro lugar da mãe, depois do pai (que não apoia tanto quanto a mãe) e da namorada/esposa/cônjuge:

\begin{tabular}{|c|c|c|c|c|c|c|c|c|c|c|c|c|c|c|}
\hline \multicolumn{15}{|c|}{ Nível de satisfação das pessoas sobre a escolha profissional ${ }^{34}$} \\
\hline & \multicolumn{2}{|l|}{ Pai } & \multicolumn{2}{|l|}{ Mãe } & \multicolumn{2}{|c|}{ Amigos } & \multicolumn{2}{|c|}{ Amigas } & \multicolumn{2}{|c|}{ Cônjuge } & \multicolumn{2}{|c|}{ Vizinhos } & \multicolumn{2}{|c|}{ Parentes } \\
\hline & RJ & AV & RJ & AV & RJ & $\mathrm{AV}$ & RJ & AV & RJ & AV & RJ & $\mathrm{AV}$ & RJ & AV \\
\hline 1 & 47,8 & 55,1 & 63,8 & 63,7 & 32,3 & 24,5 & 37,5 & 26,4 & 45,1 & 53,8 & 33,0 & 16,9 & 39,8 & 34,6 \\
\hline 2 & 10,8 & 17,2 & 13,8 & 20,6 & 32,3 & 35,0 & 30,8 & 37,7 & 14,2 & 21,1 & 22,5 & 24,5 & 19,5 & 28,8 \\
\hline 3 & 5,8 & 10,3 & 5,5 & 5,1 & 11,5 & 22,8 & 5,8 & 15,0 & 6,0 & 7,6 & 11,2 & 13,2 & 18,8 & 15,3 \\
\hline 4 & 10,1 & 3,4 & 4,8 & 1,7 & 3,6 & 5,2 & 4,4 & 5,6 & 7,5 & 1,9 & 3,0 & 7,5 & 4,3 & 5,7 \\
\hline S.O. ${ }^{35}$ & 17,3 & 5,1 & 9,0 & 1,7 & 18,7 & 8,7 & 18,3 & 11,3 & 20,3 & 3,8 & 26,3 & 30,1 & 15,2 & 11,5 \\
\hline N.D.A. & 7,9 & 8,6 & 2,7 & 6,9 & 1,4 & 3,5 & 2,9 & 3,7 & 6,7 & 11,5 & 3,7 & 7,5 & 2,1 & 3,8 \\
\hline
\end{tabular}

A justificação do apoio/aprovação das pessoas próximas é explicada na maioria das vezes porque estes querem ver o sucesso profissional e/ou a realização do indivíduo, além de entenderem que a satisfação deve ser do indivíduo. Mas os pais também se contentam com esta escolha porque gostariam de ter sido professores/as (e se espelham no filho); porque o filho seguiu a profissão da família; por orgulho que o filho tire um curso (profissional ou superior); ou porque perceberam que o filho tinha perfil para tal ofício. O prestígio e utilidade da profissão, a carreira estável e com fácil ascensão (associada ao funcionalismo público), a fácil empregabilidade (principalmente no RJ-BR) e a boa remuneração ${ }^{36}$, são outros aspectos dignos de reconhecimento das pessoas.

${ }^{34}$ Em uma escala de intensidade de 1 a 4, em que 1 significa muito e 4 significa nada. Desconsiderando-se as respostas que marcaram que esta pessoa não tem opinião ou não existe.

35 Sem Opinião.

${ }^{36}$ Este item é ressaltado em algumas respostas tanto no RJ-BR quanto em AV-PT, pois, apesar da remuneração do/a professor/a ser baixa no Brasil, as pessoas oriundas de classes mais pobres e rurais ainda consideram que esta remuneração é boa, tendo em vista que há outras ainda piores. 
A maior desaprovação (nível 4) que apareceu nas respostas foi do pai no RJ-BR (mais de 10\%) e a menor desaprovação em AV-PT por parte da mãe e cônjuge ${ }^{37}$. No entanto, os parentes, vizinhos e amigos(as) desaprovam ou apoiam bem menos esta opção. Nas explicações sobre o motivo da insatisfação destas pessoas, os inquiridos destacaram que elas na maioria desagradam-se com a baixa remuneração (no RJ-BR), a falta de reconhecimento da profissão e/ou consideram que outra área seria melhor. Os entrevistados explicam nos seus relatos que os pais preferiam que seguissem uma profissão mais rentável ou que eles achassem mais adequada, reconhecida ou com maior status, como a medicina, engenharia, advocacia.

A desaprovação da escolha profissional também acontece porque seria um ofício feminino; por ser uma profissão instável/trabalhosa ou pelo lamento desta ser a única via possível.

Nas entrevistas estas desaprovações aparecem, tanto no RJ-BR quanto em AV-PT, pois alguns amigos, amigas (principalmente os do sexo masculino) e vizinhos chacotearam os baixos rendimentos (que antigamente também eram mais pertinentes a esta profissão em Portugal) e a escolha de uma profissão feminina (no caso do RJ-BR).

Enfim, as diversas opiniões balançam entre se a carreira é boa, se é rentável, se é o que o indivíduo deseja ou se esta não é catividade de homem.

\section{Níveis de satisfação e perspectivas futuras}

Diante de tantas dúvidas e preconceitos, muitos professores se veem desmotivados e/ou ambicionam mudar de carreira. Indagados sobre as satisfações e insatisfações com a sua carreira e as suas aspirações profissionais, percebe-se (conforme 0 gráfico a seguir) que muitos docentes encontram-se descontentes com o seu ofício.

Na média geral somente $51 \%$ dos professores do RJ-BR pretendem continuar na profissão, enquanto em AV-PT 74\% querem continuar. O número de insatisfeitos é ainda maior entre os professores mais jovens (até 29 anos) somente $41 \%$ aspiram continuar na profissão no RJ-BR e em AV-PT $62 \%$ desejam continuar no seu ofício ${ }^{38}$.

${ }^{37}$ Há insatisfação da cônjuge no RJ-BR, o que aparece nas entrevistas, relacionada principalmente à baixa remuneração ou ao preconceito sofrido.

${ }^{38}$ Por vários motivos, com a idade os professores passam a querer continuar na profissão, alguns professores destacaram nas suas respostas a experiência, uma ideia mais clara da profissão, que aprendeu a gostar da profissão, que irá se aposentar (então não quer mais mudar de profissão), entre outros. 


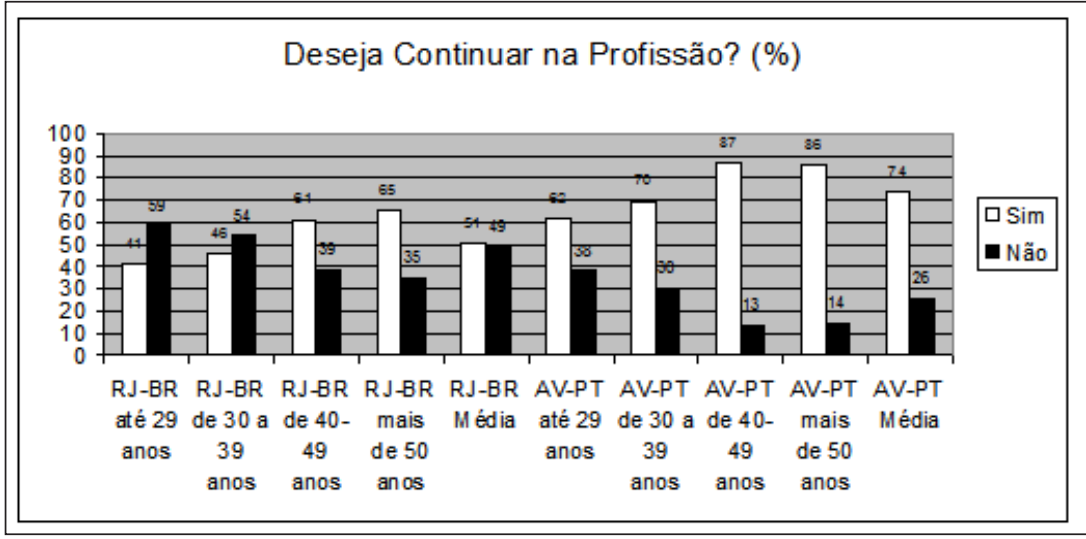

Todavia, a minoria dos professores que quer mudar de profissão almeja trabalhar em outra área fora da educação (só $5 \%$ destes professores em AV-PT e $14 \%$ do RJ-BR). A maioria das pretensões profissionais destes professores encontra-se dentro da educação: no RJ-BR a maior parte (32\%) quer ser professor do ensino superior, e em AV-PT a maioria (45\%) quer ser professor do 2. $\%$ 3. ${ }^{\circ}$ ciclo e ensino secundário ${ }^{39}$ (contudo existem outras áreas preferidas, por exemplo, os setores administrativos da educação).

\section{Desempenho profissional segundo o gênero - a presença do preconceito}

Quem tem mais aptidão para o magistério: o homem ou a mulher? A partir das respostas a esta pergunta (destacada no gráfico a seguir), os professores demonstraram suas representações de gênero, em que encontramos ampla possibilidade para analisar as diferenciações dos papéis sexuais e as habilidades necessárias para ser docente.

A maioria das respostas à questão aponta para uma indiferença do gênero na aptidão docente, porém há que se destacar dois pontos que surpreenderam:

a) A existência de muitos professores (principalmente no RJ-BR, com mais de $18 \%$ das respostas) que consideraram que a mulher tem maior aptidão para o magistério neste segmento (o que pode ser analisado até como uma des-

${ }^{39}$ Equivalente à 5. ${ }^{\mathrm{a}}$ a $8 .^{\mathrm{a}}$ série e ensino médio no Brasil. 


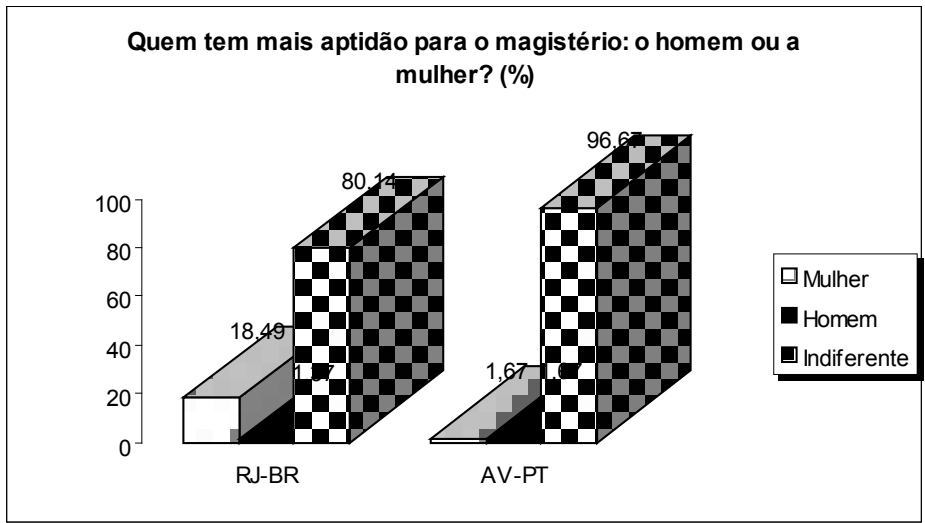

valorização da sua própria capacidade profissional ou do seu próprio gênero). Ressalta-se que a maioria dos inqueridos que deram esta resposta optou pela sua profissão por gosto e não por falta de opção. Por isso, concluimos que esta opinião perpassa a sociedade e este indivíduo a abarca como sua opinião (mesmo ao optar por uma área considerada feminina).

b) Além das respostas que assinalaram que algum gênero (homem ou mulher) tem maior aptidão para o magistério, muitos professores que marcaram a opção indiferente apresentaram justificativas desta resposta que, mesmo assim, segregavam as aptidões dos homens e das mulheres.

Dentre as justificativas referentes a esta questão aparecem muitas representações e/ou preconceitos de gênero presentes na sociedade. Citaremos alguns exemplos destas explicações:

- o homem é mais profissional e tem mais controle sobre a criança (a "temerosa" figura paterna);

- homem e mulher têm cada um o seu papel de gênero;

- há necessidade de vocação para o magistério, existe um perfil/aptidão "inato" para esta profissão, ou consideram que esta profissão é de mulheres e que necessita de atributos femininos (o que leva um homem a escolher e exercer esta profissão se ele não considera que esta profissão pode ser exercida por homens?);

- a consideração de que a mulher é melhor professora por ser sensível/ paciente/carinhosa (o homem não tem esses características?) ou por seu lado maternal (também associado à educação de infância).

Mesmo diante destas explicações que ainda segregam os gêneros na carreira do magistério, a maioria das respostas explica que há a necessidade de uma escolha efetuada por gosto/interesse/amor e que não há uma aptidão específica 
para cada sexo. Muitos justificam também que a qualidade para a docência depende de uma boa formação profissional, de competência, profissionalismo, dedicação e comprometimento.

Ainda considerando questões de gênero, é importante avaliar as experiências de discriminações que os professores vivenciaram ou presenciaram. Conforme percebe-se no gráfico, no RJ-BR, 43,54\% dos inquiridos já presenciaram alguma discriminação, já em AV-PT somente 15,25\% (é importante referir que ninguém mencionou o preconceito referente à homossexualidade):

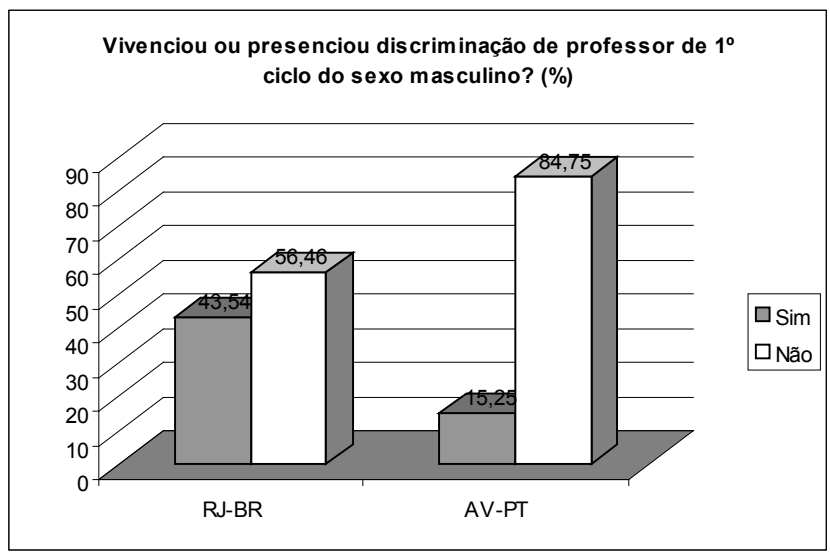

Como este assunto contempla tabus, ele envolve muita habilidade e cautela tanto nas entrevistas quanto nos inquéritos distribuídos (por isso certas perguntas não deveriam ser feitas no questionário). Portanto, nas entrevistas os relatos foram recheados de emoções que envolveram a não aceitação familiar da escolha profissional, a implicância de colegas associada ao baixo rendimento e homossexualismo, os olhares "estranhadores", a discriminação declarada e anônima ${ }^{40}$, entre outras.

Nos questionários foram destacados os preconceitos relacionados com o homossexualismo ${ }^{41}$; o medo da pedofilia e do assédio sexual ${ }^{42}$; a timidez frente a um homem; as generalizações de que o homem é incapaz de lidar com crianças; do professor.

${ }^{40}$ Até mesmo uma carta anônima foi enviada para uma escola (no RJ-BR) pedindo a saída

${ }^{41}$ Ouvimos declarações preconceituosas até mesmo nos setores administrativos da educação quando recolhemos dados para a nossa investigação, pois ao falarmos que pesquisávamos sobre os professores do sexo masculino no ensino primário responderam (em mais de um lugar) que "homem nós não iríamos encontrar", insinuando que só havia professores homossexuais neste segmento.

${ }^{42}$ Como se as mulheres não assediassem nem fossem pedófilas. 
um ofício pouco rentável que não é para homem (muito menos para os "chefes de família"); o pressuposto de que todos os docentes do ensino primário são mulheres (por exemplo, nos documentos em que aparece "professora").

Diante das respostas dos questionários e das entrevistas realizadas, é possível adiantar algumas respostas à pergunta "Por que poucos homens escolhem o magistério primário?": porque há falta de informação/divulgação desta profissão para o sexo masculino; há dificuldade e desvalorização da profissão (inclusive na remuneração, reconhecimento e status); existem questões culturais que divulgam esta profissão como feminina (e como associada à necessidade de atributos "maternais/feminis"), além de existirem preconceitos ao homem que escolhe esta profissão (que distanciam o homem dela, pois ninguém deseja ser alvo de discriminações).

\section{Superando estereótipos de gênero - breves considerações finais}

Uma das questões mais relevantes desta investigação é apreender a motivação da escolha profissional dos professores, até porque, como destaca Galbraith (1992), um melhor entendimento das escolhas de quem opta por carreiras atípicas para seu gênero pode servir de base para intervenções e aumento do alcance das opções profissionais consideradas pelos jovens, assim reduzindo a segregação na sociedade.

Este trabalho lembra que os/as docentes são as pessoas que têm acesso sucessivo com o cotidiano (e as dificuldades da sala de aula), por isso são eles que podem tentar aprimorar os currículos, as práticas educativas e a realidade escolar, além de potencializar as efetivas transformações educacionais. Louro (2000, p. 56-57) destaca que as práticas escolares e os currículos não são meros transmissores de representações sociais, pois carregam e produzem representações. O silenciamento, a marginalização e a deslegitimação em torno das identidades sexuais e de gênero constitui uma forma de representá-las.

Assim, a presença de professores do sexo masculino na docência do ensino primário é uma forma de inserir as questões de gênero na educação e demonstrar às crianças na escola que o homem também pode escolher essa atividade e ter sucesso. Nas entrevistas que realizamos, tanto em AV-PT como no RJ-BR, os professores destacam que grande parte das crianças (da sua sala de aula e de outras classes da escola) e seus pais e mães gostam (ou até preferem) estes professores, pois, contrariando os estereótipos, percebe-se que eles têm habilidades para o exercício profissional. Isto tem como consequência a divul- 
gação (consciente ou inconsciente) de que nem a docência nem as qualidades "tradicionalmente femininas" são específicas das mulheres.

Galbraith (1992, p. 251-252) percebeu, na sua investigação, que os homens em ocupações não tradicionais (enfermeiros e professores primários) adicionavam dimensões na sua vida que não são vistas como papéis tradicionais masculinos em vez de abandonarem sua masculinidade. $\mathrm{O}$ autor mostra que se a mulher pode manter sua perspectiva feminina e ter benefícios de uma carreira masculina, os homens também podem reter sua perspectiva masculina e adicionar dimensões dos componentes tradicionalmente femininos à sua experiência ocupacional (como comunicação e fatores de relacionamento). Sayão (2005) também aponta que a inserção dos homens em profissões femininas proporciona uma revalorização da masculinidade.

Ainda que os docentes do sexo masculino queiram demarcar a sua diferença das mulheres, como analisa Cardoso (2006, p. 3-4) que os docentes "estão estabelecendo diferenças, fabricando o outro por meio de suas representações", assim a diferença atribuída à prática de homens e mulheres nesse mesmo trabalho revela que "embora haja um propósito de pensar as relações de gênero de uma forma mais igualitária, na prática, os professores homens continuam se representando de forma desigual em relação às professoras mulheres".

Dessa maneira, Williams (1995, p. 188) conclui no seu livro sobre os homens que trabalham em profissões "tradicionalmente femininas" que a presença deles nestas profissões pode não transformar diretamente a segregação de gênero no mercado de trabalho porque, apesar do preconceito que sofrem, eles comumente "aproveitam-se" das vantagens da masculinidade na sociedade.

Também a investigação empírica internacional que alega efeitos negativos da feminização é virtualmente inexistente, como demonstrado por Driessen (2007, p. 189), por isso é frágil o argumento de que há necessidade de modelos masculinos na escola e que a feminização do ensino pode causar uma falta de modelos masculinos (que poderia ter consequências negativas para o rendimento e a conduta dos alunos, principalmente dos rapazes). $\mathrm{O}$ autor conclui que não existe evidência empírica de que ter mais homens à frente da sala de aula conduza a uma melhor realização e/ou atitudes e comportamentos mais favoráveis por parte dos rapazes ou meninas. Mas ele também aponta que isso não significa que não deva ser estimulada uma distribuição equilibrada de homens e mulheres na educação, não apenas no ensino, mas em todas as funções.

Porém, conforme verificamos nos relatos dos entrevistados, as crianças com que estes homens lidam poderiam se identificar com novos modelos masculinos exercendo estas atividades. A observação destes modelos poderia começar a mudar a definição da masculinidade e incluir as qualidades ditas "femininas" nesta. Pois como assinalam Fávero e Salgado (2006, p. 4), há uma articulação 
entre as representações das áreas de conhecimento e as representações de gênero, o que trás uma séria implicação para a questão das escolhas profissionais de homens e mulheres. Assim, ver homens na docência primária pode influenciar outros homens/meninos a escolheram tal profissão.

Dessa forma, mesmo que esses homens pudessem ter concepções de gênero não totalmente igualitárias (o que também percebe-se com o nosso trabalho em algumas das respostas sobre quem tem maior aptidão profissional para a docência), sua presença nestas ocupações pode mudar as distinções entre homem e mulher - o que Williams (1995) destaca como uma etapa importante para a realização da igualdade de gênero.

Além disso, como adverte Silva (2002), o currículo torna-se um local de produção da identidade e alteridade, no ponto de intersecção entre poder e representação. É precisamente nesse ponto que o currículo tal como o conhecimento se tornam um terreno de luta em torno da representação. Luta que, de acordo com Louro (2000, p. 57), geralmente é dominada pela voz socialmente autorizada que inclui e exclui sujeitos e conhecimentos, determinando não apenas quais as identidades ou os saberes que podem integrar o currículo, mas também como essas identidades e saberes deverão ser aí representados.

Neste terreno de lutas onde as vozes autorizadas determinam como as identidades e saberes são representados, destaca-se os/as docentes como representantes tanto da "mudança" como da "estagnação", pois eles têm a legitimidade para ensinar o currículo. Portanto, ouvir a parcela de professores que é minoria absoluta no magistério primário (os professores do sexo masculino) possibilita mostrar que a docência infantil não é um atributo apenas feminino e permite que se levantem outras vozes masculinas na educação que surgem no ato de recontar/reescrever os meandros da sua escolha e exercício profissional.

A potencialidade destas novas vozes mostra que as discriminações dos papéis relacionados ao gênero na educação são provocadas por forças sociais, mas que pode haver uma resistência a estas determinações, resistência demarcada no sucesso desses homens na docência e no seu reconhecimento por parte das crianças e seus pais e mães.

\section{REFERÊNCIAS}

ABRANCHES, G.; CARVALHO, E. Linguagem, poder, educação: o sexo dos B,A, BAs. Lisboa: Cadernos Coeducação. Comissão para a Igualdade e para os direitos das mulheres, 2000. 
ABREU, J. J. V. D. A inserção do professor do sexo masculino no magistério primário de Teresina (PI). In: CONGRESSO BRASILEIRO DE HISTÓRIA DA EDUCAÇÃO: História e Memória da Educação Brasileira, II, 2002, Natal, Brasil, Anais... Natal: 2002.

ALMEIDA, J. S. D. Mulheres na escola: algumas reflexões sobre o magistério feminino. Cadernos de Pesquisa, v. 96, n. p. 71-78, fev. 1996.

APPLE, M. W. Ensino e trabalho feminino: uma análise comparativa da história e ideologia. Cadernos de Pesquisa, v. 64, n. 14-23, fev. 1988.

BERTELLI, E. Os não ditos e os vividos: trajetórias masculinas numa "profissão feminina". In: SEMINÁRIO INTERNACIONAL FAZENDO GÊNERO 7: Gênero e Preconceitos, Santa Catarina: Universidade Federal de Santa Catarina, Anais... Santa Catariana: 2006.

BETTO, F. Porque escrevo? In: BIANCHETTI, L. (Ed.). Trama e texto: leitura crítica: escrita criativa. 2. ed. São Paulo: Summus, 2002.

BLANCHET, A.; GOTMAN, A. L'enquete et ses méthodes: L'entretien. Paris: Nathan Université, 2001.

BOTIA, A. B. ¿De nobis ipsis silemus?: Epistemología de la investigación biográfico-narrativa en educación. 2002. Disponível em: <http://redie.ens.uabc.mx/vol4no1/ contenido-bolivar.html>. Acesso em: 06/01/2005.

BRASIL. Estatísticas dos professores no Brasil. Brasil: INEP, 2003.

BRUSCHINI, C.; AMADO, T. Estudos sobre mulher e educação. Cadernos de Pesquisa, v. 64 , n. p. 4-13, fev. 1988.

CARDOSO, F. A. A identidade de professores homens na docência com crianças: homens fora de lugar? In: SEMINÁRIO INTERNACIONAL FAZENDO GÊNERO 7: Gênero e Preconceitos, Santa Catarina: Universidade Federal de Santa Catarina, Anais... Santa Catariana: 2006.

CARNEIRO, R. O futuro da educação em Portugal - tendências e oportunidades: um estudo de reflexão prospectiva. 2000. Disponível em: <www.cgee.org.br/atividades/ redirKori/2911>. Acesso em: 05/06/2013.

CARVALHO, M. P. D. Vozes masculinas numa profissão feminina. Revista Estudos Feministas, v. 6, n. 2, p. 406-422, 1998.

CATANI, D. B.; BUENO, B. O.; SOUSA, C. P. D. Os homens e o magistério: as vozes masculinas nas narrativas de formação. In: CATANI, D. B.; BUENO, B. O. et al. (Eds./ Orgs.). A vida e o ofício dos professores. São Paulo: Escrituras, 2000.

CONSELHO DA EUROPA. Recomendação $n .^{\circ} 5$ (90) 4 do Comitê de Ministros aos Estados Membros Sobre a Eliminação do Sexismo na Linguagem. 1990. Disponível em: <http://www.apem-estudos.org/Rec\%20linguagem\%20CEuropa.pdf $>$. Acesso em: $05 / 06 / 2013$. 
DEMARTINI, Z.; ANTUNES, F. Magistério primário: profissão feminina, carreira masculina. Cadernos de Pesquisa, n. 86, p. 5-14, ago. 1993.

DRIESSEN, G. The feminization of primary education: effects of theachers' sex on pupil achievement, attitudes and behaviour. Review of Education, n. 53, p. 183-203, 2007.

FÁVERO, M. H.; SALGADO, J. S. Professores e professoras da minha vida: as representações sociais de gênero do magistério. In: SEMINÁRIO INTERNACIONAL FAZENDO GÊNERO 7, Florianópolis, Santa Catarina: Universidade Federal de Santa Catarina, Anais... Santa Catariana: 2006.

FENTRESS, J.; WICKHAM, C. Memória social: Novas perspectivas sobre o passado. Lisboa: Teorema, 1992.

FERNANDES, M. C. D. S. G. Escolha profissional e prática docente: o discurso de professores do ensino superior privado. In: REUNIÃO ANUAL DAANPED, 27, Caxambu, MG, Anais... Caxambu, MG: 2004.

FOUCAULT, M. História da sexualidade 1: a vontade de saber. 10. ed. Rio de Janeiro: Graal, 1990.

. Microfisica do poder. Trad. de: R. Machado. Rio de Janeiro: Edições Graal, 1979.

GALBRAITH, M. Understanding career choices of men in elementary education. Journal of Educational Research, v. 85, n. 4, p. 246-253, March/April 1992.

GIASE. Séries cronológicas, docentes - 1985-2005. Lisboa: Portugal - GIASE, 2006.

HALL, S. The spectacle of the 'other'. In: (Ed.). Representation: cultural representations and signifying practices. London: Sage, 1997a. p. 223-290.

. The work of representation. In: (Ed.). Representation: cultural representations and signifying practices. London: Sage 1997b. p. 13-74.

LOURO, G. L. Currículo, gênero e sexualidade. Porto: Porto Editora, 2000.

MÓNICA, M. F. Educação e sociedade no Portugal de Salazar. Lisboa: Editora Presença/ Gabinete de Investigações Sociais, 1978.

PINCINATO, D. A. V. História do magistério: experiências masculinas na carreira administrativa no estado de São Paulo (1950-1980). In: REUNIÃO DA ANPED, 27, Caxambu, MG, Anais... Caxambu, MG: 2004.

PINCINATO, D. A. V.; BUENO, B. O. Homens, profissão docente e cultura do magistério no Brasil (1950-1989). In: CONGRESSO LUSO-BRASILEIRO DE HISTÓRIA DA EDUCAÇÃO, VII, Universidade do Porto, Anais... Porto: 2008.

RABELO, A. A Memória das Normalistas do IESK de Campo Grande/RJ. Dissertação (Mestrado em Memória Social e Documento) - UNIRIO, Rio de Janeiro, 2004.

. A remuneração do professor é baixa ou alta? Uma contraposição de diferentes referenciais. Educação em Revista, v. 26, n. 01, p. 57-88, abr. 2010. 
RÊGO, M. D. C. D. C. A figura masculina na docência do ensino primário: Um corpo estranho no cotidiano das escolas públicas primárias do Rio de Janeiro (Brasil) e Aveiro (Portugal). Tese (Doutorado) - Universidade de Aveiro, Aveiro, 2008.

. Para uma cidadania activa: a igualdade de homens e mulheres. Portugal: Instituto do Emprego e Formação Profissional, 2004.

REIS, M. A. (Re)Invenção da escola pública: sexualidade e formação da jovem professora. Tese (Doutorado em Educação) - UFF, Rio de Janeiro, 2002.

SARMENTO, T. Correr o risco: ser homem numa profissão 'naturalmente' feminina. In: CONGRESSO PORTUGUÊS DE SOCIOLOGIA: Sociedades Contemporâneas: Reflexividade e Ação, Braga, Portugal: Anais... Braga: 2002.

SAYÃO, D. T. Relações de gênero e trabalho docente na educação infantil: um estudo de professores em creche. 273 p. Tese (Doutorado em Educação) - Programa de Pós-Graduação em Educação, Centro de Ciências da Educação, Universidade Federal de Santa Catarina, Florianópolis, 2005.

SILVA, T. T. D. A poética e a política do currículo como representação [Electronic Version]. Educação on-line. 2002. Disponível em: <http://www.educacaoonline.pro. br/a_poetica_e_a_politica.asp $>$. Acesso em: 21/07/2005.

WILLIAMS, C. Still a man's world: mens do women's work. Berkeley, CA: University of California Press, 1995.

Texto recebido em 14 de abril de 2011.

Texto aprovado em 23 de novembro de 2012. 